Preference is given to letters commenting on contributions published recently in the JRSM. They should not exceed 300 words and should be typed double spaced

\section{Reducing the toll of road traffic accidents}

Rodger Charlton and Gary Smith made numerous important and useful points in their editorial (October $2003 \mathrm{JRSM}^{1}$ ) but it was disappointing to see them fail to give credit to what has actually been achieved in reducing the number of casualties from road traffic accidents. They have overlooked the point that, in about thirty years during which there has been an enormous increase in the number of vehicles and the number of miles travelled, road deaths have actually been halved in the UK. This has been achieved by a combination of the drink-drive laws, the use of seat belts, improved vehicle design and more motorways, as well as traffic calming and control. It is wrong to give the impression that an increasing toll of road casualties is being ignored.

Unfortunately, in their suggestions to improve the situation further, the authors omitted to mention that pedestrians and cyclists are not subject to the drink-drive legal limit and cannot be breath-tested, and whilst criticizing the use of mobile telephones did not at the same time point out the dangers of selecting, lighting and smoking cigarettes or of using visual display panels associated with tracking devices.

The fact that progress is still being made in road safety is evident from the latest figures which show that there was a 3\% reduction in road casualties between 2001 and 2002 whilst the reduction in road deaths was $19 \%$. There is certainly still a great deal that can be done, but please give credit to those people who have worked hard for many years to bring about substantial improvements.

\section{Ronald C Denney}

Manteo, 8 Letter Box Lane, Sevenoaks, Kent TN13 1SN, UK

\section{REFERENCE}

1 Charlton R, Smith G. How to reduce the toll of road traffic accidents. J R Soc Med 2003;96:475-6

Rodger Charlton and Gary Smith (October 2003, JRSM ${ }^{1}$ ) refer to the sizeable number of deaths in motorcyclists. Although constituting only $4 \%$ of total road traffic accidents they contribute $14 \%$ of the deaths. $80 \%$ of motorcycle deaths are from head injury. I have patented and produced a prototype of a new design for head protection which has been shown by the Transport Research Laboratory to provide between 47-59\% more protection against rotational forces than conventional helmets. This is a development of my observation that the scalp in the human head provides most of the protection against rotational forces, a major factor in head injury: the Phillips Helmet has a membrane which simulates the scalp in being able to slide over the surface of the shell as the scalp does over the skull. That existing helmet manufacturers are reluctant to take on this invention is maybe not surprising. More disturbing is the lack of response from the Department of Transport, to which I have written twice.

\section{K D Phillips}

10 Harley Street, London W1G 9PF, UK

E-mail: k.d.phillips@which.net

\section{REFERENCE}

1 Charlton R, Smith G. How to reduce the toll of road traffic accidents. J $R$ Soc Med 2003;96:475-6

Rodger Charlton and Gary Smith (October 2003, JRSM $M^{1}$ ) provide useful suggestions on how to reduce the toll of road traffic accidents. However, I am surprised that they make no mention of the need to develop a more robust system of renewal of driving licences, particularly in the elderly population. $^{2}$ Although I have no concrete evidence whatsoever, personal observation over many years has convinced me that accidents on the roads are increasingly attributable to elderly drivers, many of whom have poor reaction times, poor memory, poor concentration and poor visual acuity, and are physically very frail.

To test this hypothesis would not be easy since the age of the responsible driver would need to be established, and this in turn would necessitate identification of responsibility. I wonder if the police are sometimes reluctant to prosecute these drivers for fear of being accused of ageism? I believe that a more robust system of reassessment would substantially reduce the number of injuries in all age groups.

\section{John Bache}

Accident and Emergency Department, Leighton Hospital,

Crewe, Cheshire CWI 4QJ, UK

\section{REFERENCES}

1 Charlton R, Smith G. How to reduce the toll of road traffic accidents. $R$ Soc Med 2003;96:475-6

2 Carvel D. System of renewal of driving licences for elderly people needs overhauling. BMJ 2002;324:1154

Rodger Charlton and Gary Smith (October 2003 JRSM ${ }^{1}$ ) draw attention to several modifiable factors that might reduce the toll of road traffic accidents, but overlook another that may be under-recognized in the UKprescription and over-the-counter medicines and illicit drugs. In addition to the well-known side-effects of the antidepressants, over a hundred medicines (antihistamines, opioids, muscarinic antagonists) have been recognized as impairing performance. ${ }^{2}$ While the incidence of involvement of medicines in UK accidents has been reported to be 
fairly static at $6 \%,{ }^{2}$ studies in Scandinavia (where the adverse potential of medicines seems to have a higher profile) suggest medicines and/or illicit drugs may be implicated in more than $20 \%$ of single-vehicle fatal accidents. ${ }^{3}$ Although the total number of apprehensions by Norwegian police for accidents, dangerous or erratic driving due to a suspicion of influence by alcohol or medicines and/or illicit drugs has remained relatively constant since 1983, those associated with alcohol have declined, with an increase in cases linked to medicines and/ or drugs. ${ }^{4,5}$ Furthermore, compared with 'drunk' drivers, those arrested for 'drugged' driving have a higher standardized mortality ratio $^{6}$ and are more likely to reoffend. ${ }^{7}$ Impaired driving during the morning after taking a hypnotic (barbiturate, benzodiazepine, or zopiclone) returned to 'control' levels in the afternoon. ${ }^{8}$ In Canada, compared with 'undrugged' drivers, those taking a hypnotic for the first time had an odds ratio of 9.1 for acquiring a road-accident-related injury during the initial week, and 13.5 while taking an anxiolytic. ${ }^{9}$ These ratios declined to 3.9 and 2.5, respectively, after four weeks.

The International Council on Alcohol, Drugs and Traffic Safety has published prescribing and dispensing guidelines for medicinal drugs known to affect driving performance. ${ }^{10}$ While it may be impractical to expect patients taking these medicines to stop driving, physicians and pharmacists can probably do more to highlight the impaired performance associated with many medicines and of possible additional adverse effects when they are combined with other medicines and/or illicit drugs or alcohol.

\section{Christopher D R Dunn ${ }^{1}$}

\section{Asbjørg S Christophersen ${ }^{1,2}$}

${ }^{1}$ Social Pharmacy, University of Oslo, PO Box 1068, Blindern, 0316 Oslo; ${ }^{2}$ Norwegian Institute of Public Health, Division of Forensic Toxicology and Drugs Abuse, PO 4403 Nydalen, 0403 Oslo, Norway

E-mail: c.d.r.dunn@farmasi.uio.no

\section{REFERENCES}

1 Charlton R, Smith G. How to reduce the toll of road traffic accidents. J $R$ Soc Med 2003;96:475-6

2 Department for Transport. Road Safety Research Compendium 2002/2003: Theme 3: impairment. http://www.dft.gov.uk/stellent/groups/dft_rdsafety/ documents/pdf/dft_rdsafety_pdf_504579.pdf

3 Gjerde H, Beylich K-M, Mørland J. Incidence of alcohol and drugs in fatally injured car drivers in Norway. Accid Anal Prev 1993;25:473-83

4 Christophersen AS. The occurrence of drugged driving in Norwayexisting problems and solutions. Blutalkohol 2000;37:20-7

5 Folkehelseinstituttet [http://www.fhi.no/tema/rettstoks/statistikk/]

6 Skurtveit S, Christophersen AS, Grung M, Mørland J. Increased mortality among previously apprehended drunken and drugged drivers. Drug Alcohol Depend 2002;68:143-50

7 Christophersen AS, Skurtveit, S, Grung M, Mørland J. Rearrest rates among Norwegian drugged drivers compared with drunken drivers. Drug Alcohol Depend 2002;66:85-92

8 O'Hanlon JF, Brookhuis KA, Louwerens JW, Volkerts ER. Performance testing as part of drug registration. In: O'Hanlon JF,
deGrier JJ, eds. Drugs and Driving. London: Taylor \& Francis, 1986. $311-20$

9 Neutal CI. Risk of traffic accident injury after a prescription for a benzodiazepine. Ann Epidemiol 1995;5:239-44

10 The ICADTS Working Group. Prescribing and Dispensing Guidelines for Medicinal Drugs Affecting Driving Performance. Ontario: International Council on Alcohol, Drugs and Traffic Safety, 2001

\section{Autonomic dysreflexia}

Dr McBride and her colleagues (July 2003, JRSM ${ }^{1}$ ) describe a patient with spinal cord injury whose blood pressure rose threefold on sexual stimulation. We note the published correction $^{2}$ concerning level of sympathetic outflow. The propensity of the sympathetic system to produce a mass response at varying intervals after the injury has been likened to development of spasticity in the motor system. Some people develop only mild dysreflexic symptoms, which they learn to associate with changes in the insensate part of the body such as a full bladder. ${ }^{3}$ Certain disabled athletes induce mild dysreflexia to enhance their achievements in sports, a phenomenon referred to as 'boosting'. ${ }^{4}$

A rise in blood pressure during sexual activity, especially at the time of ejaculation, has been well documented in both normal individuals and those with spinal cord injury (SCI), the magnitude of the rise being greater in the latter group. ${ }^{5}$ Hypotensive agents, such as glyceryl trinitrate spray or captopril, may be used when symptoms arise or prophylactically before sexual activity, to mitigate the resultant hypertension. Electroejaculation, a more painful procedure, is commonly employed in SCI individuals to obtain semen for assisted fertilization techniques. In our experience patients usually tolerate this procedure without need for medication (only 4 of 64 patients in our series who underwent assisted ejaculation developed dysreflexic symptoms, the symptoms settling without any pharmacological intervention in 3 and with glyceryl trinitrate spray in 1 ). It is also noteworthy that only $50 \%$ of patients who developed a vasomotor headache had a significant rise in blood pressure. ${ }^{6}$

The patient reported by McBride et al. had sustained his injury 36 years earlier and had engaged in sexual activity without headache until the onset of autonomic dysreflexia 3 years previously. The report does not make clear whether other neurological disorders were excluded - such as syringomyelia, which could manifest as new onset autonomic dysreflexia. The relation between the patient's erectile dysfunction and his autonomic dysreflexia is weak and both may reflect deterioration in neurological status.

Thus it is difficult to agree with the authors' conclusion that their patient with autonomic dysreflexia should abstain from sexual activity. The best course of action, in our opinion, would be a thorough investigation to exclude any neurological changes, followed by a full explanation and a 
trial of sexual intercourse with access to hypotensive medication such as glyceryl trinitrate spray to control the symptoms of autonomic dysreflexia should they arise.

\section{P Thumbikat}

\section{P R Tophill}

Princess Royal Spinal Injuries Centre, Northern General Hospital, Sheffield S5 7AU Correspondence to: Pradeep Thumbikat

E-mail: pradeep.thumbikat@sth.nhs.uk

\section{REFERENCES}

1 McBride F, Quah SP, Scott ME, Dinsmore W. Tripling of blood pressure by sexual stimulation in a man with spinal cord injury. $J R$ Soc Med 2003;96:349-50

2 Correction: Tripling of blood pressure by sexual stimulation in a man with spinal cord injury. $J$ R Soc Med 2003;96:574

3 Teasell RW, Arnold JM, Krassioukov A, Delaney GA. Cardiovascular consequences of loss of supraspinal control of the sympathetic nervous system after spinal cord injury. Arch Phys Med Rehabil 2000;81:506-16

4 Burnham R, et al. Intentional induction of autonomic dysreflexia among quadriplegic athletes for performance enhancement: efficacy, safety and mechanism of action. Clin J Sport Med 1994;4:1-10

5 Stein RA. Cardiovascular response to sexual activity. Am J Cardiol 2000;86(suppl):27F-29F

6 Tophill PR. Assisted Ejaculation Techniques in Spinal Cord Injured Men [Thesis]. University of Sheffield, 1996

\section{Authors' reply}

We welcome the correspondence from Mr Thumbikat and Mr Tophill outlining their experience with patients with spinal cord injury. We agree that the possibility of other diagnoses for the late onset of autonomic dysreflexia should be considered and these were excluded following referral to a consultant neurologist. In this patient treatment of erectile dysfunction was discussed with regard to using agents which would simultaneously reduce his blood pressure. In view of the patient's low resting blood pressure $(93 / 50 \mathrm{mmHg})$ and extreme rise at ejaculation $(325 / 210 \mathrm{mmHg})$ the patient (not ourselves) decided against pursuing treatment any further for his erectile dysfunction.

\section{Fiona McBride}

Wallace Dinsmore

Royal Victorial Hospital, Belfast BT12 6BA

Northern Ireland, UK

\section{Preputioplasty}

Mr Barber and his colleagues describe parents' evaluations of preputioplasty (September 2003, JRSM ${ }^{1}$ ). We are concerned that in $40 \%$ of the children the main indication was asymptomatic phimosis without a history of either recurrent balanoposthitis or voiding dysfunction. In our opinion this group of patients do not require surgical intervention and can safely be reassured and discharged. Our own surgical preference in the management of symptomatic patients is lateral preputioplasty. This procedure involves two laterally placed vertical incisions over the stenotic preputial bands which are subsequently closed horizontally. ${ }^{2}$ It provides excellent symptom relief and avoids the unsightly cleft left by a single dorsal incision over a stenotic preputial band. Barber et al. had a rather poor success rate in preventing recurrent balanoposthitis. We think that a severely scarred foreskin is best managed by circumcision. $^{3}$

\section{Tim Lane}

\section{Marie South $^{1}$}

Queen Mary Westfield School of Medicine, London; ${ }^{1}$ Maidstone Hospital, Maidstone, Kent, UK

\section{REFERENCES}

1 Barber NJ, Chappell B, Carter PG, Britton JP. Is preputioplasty effective and acceptable? J R Soc Med 2003;96:452-3

2 Lane TM, South LM. Lateral preputioplasty for phimosis. J R Coll Surg Edinb 1999;44:310-12

3 Lane TM, South LM. Inappropriate applications of preputioplasty. $J R$ Coll Surg Edinb 2000;45:139-40

\section{Public understanding of science}

How right Dr Baron is (October 2003, $J R S M^{1}$ ): the public does need to be more informed about science. C P Snow wrote of the two cultures 'which are for the most part expressed in two languages'. ${ }^{2}$ Each science has its own language, sometimes called jargon; without these special languages, academic study and accumulation of knowledge would be impossible. Some individuals have exceptional ability to explain scientific ideas in everyday language but this does not do away with the need for the languages of science. One frequently hears today of changing hearts and minds, but the heart is merely a pumping organ and mind a collective noun for many different brain functions. Words such as seeing, memory and emotion describe not single entities but complex cerebral functions. In trying to keep track of developments the public needs to be aware of cultural and language differences and to recognize that, in the phase of problem-solving, scientists may themselves be divided.

F E James

9 Mullings Court, Dollar Street, Cirencester GL7 2AW, UK

\section{REFERENCES}

1 Baron JH. What should the citizen know about 'science'? J R Soc Med 2003;96:509-11

2 Snow CP. The Two Cultures and the Scientific Revolution. Cambridge: Cambridge University Press, 1959

\section{Philoctetes}

To an archaeologist who specializes in disease and medical practice in the Aegean Bronze Age, ${ }^{1}$ the article by Dr Johnson (October $2003 J R S M^{2}$ ) seems rather curious. 
Whilst the mythology on which he writes may have been believed to be true at the time that the Athenian playwright Sophocles (c.496-406 вс) wrote them or indeed when the potter made the lekythos illustrated in the article, there is absolutely no evidence to show an historical or cultural link with the Late Bronze Age. His proposal that the story originated in 'the 13th century BCE' is therefore pure speculation.

Johnson's retrospective diagnosis of osteomyelitis may be interesting in itself, but Sophocles and even Homer are not known for their medical texts and we cannot guarantee accuracy in their descriptions; even Hippocrates got things wrong. Plays such as Philoctetes, written at the very end of the 5th century $\mathrm{BC}$, were designed partly to give an historical legitimacy, however imaginary, to an Athens in rapid decline. We must not be misled into thinking that, by examining Sophocles' play, we can learn anything about disease in the period when the Siege of Troy is supposed to have happened, at the end of the Late Bronze Age eight hundred years earlier.

\section{Robert Arnott}

Centre for the History of Medicine, University of Birmingham Medical School, Birmingham, UK

E-mail: r.g.arnott@bham.ac.uk

\section{REFERENCES}

1 Arnott R. Healing and medicine in the Aegean Bronze Age. J R Soc Med 1996;89:265-70

2 Johnson HA. The foot that stalled a thousand ships: a controversial case from the 13th century BCE. J R Soc Med 2003;96:507-8
Dr Johnson offers a plausible interpretation of the lesion on Philoctetes' leg_osteomyelitis (October 2003, JRSM $M^{1}$ ). May I add a note on the social and ethical aspects of the story, which have modern resonance? In Sophocles' play we see a respectable man rejected by his own comrades when afflicted with the stigma of disability. ${ }^{2}$ Odysseus, elsewhere heroic but here an opportunistic utilitarian, promises glory to Neoptolemus if he can win Philoctetes' trust and, by betraying him, secure the bow with which the Trojan War can be won. Torn by the competing ethical pressures, Neoptolemus rejects this proposal and persuades Odysseus to let Philoctetes rejoin the expedition. The play illustrates a conflict between individual and collective loyalties. The theme of contrasting balancing powers is also evident in the symbolism of the snake: both the cause of Philoctetes' misery and also the symbol of Asclepius, it could bring calamity or good fortune alike. This symbolism of the snake and its effect on health and wellbeing is yet another illustration of showing the antithesis encountered throughout Sophocles' of complex human behaviour.

\section{Andreas K Demetriades}

Department of Orthopaedics, Guy's Hospital, London SE1 9RT, UK

\section{REFERENCES}

1 Johnson HA. The foot that stalled a thousand ships: a controversial case from the 13th century BCE. J R Soc Med 2003;96:507-8

2 Sophocles. Philoctetes. In: The Loeb Classical Library: Sophocles II (trans Lloyd-Jones M). Cambridge, MA: Harvard University Press, 1994 